University of Nebraska - Lincoln

DigitalCommons@University of Nebraska - Lincoln

Chemical and Biomolecular Engineering -- All

Faculty Papers

Chemical and Biomolecular Engineering,

Department of

2018

\title{
Establishment of a Human iPSC- and Nanofiber-Based \\ Microphysiological Blood-Brain Barrier System
}

\author{
Dianjun Qi \\ University of Nebraska Medical Center \\ Shaohua Wu \\ University of Nebraska Medical Center \\ Haishuang Lin \\ University of Nebraska - Lincoln, hlin9@unl.edu \\ Mitchell A. Kuss \\ University of Nebraska Medical Center \\ Yuguo Lei \\ University of Nebraska - Lincoln, ylei14@unl.edu
}

See next page for additional authors

Follow this and additional works at: https://digitalcommons.unl.edu/chemengall

Qi, Dianjun; Wu, Shaohua; Lin, Haishuang; Kuss, Mitchell A.; Lei, Yuguo; Krasnoslobodtsev, Alexey; Ahmed, Shaheen; Zhang, Chi; Kim, Hyung Joon; Jiang, Peng; and Duan, Bin, "Establishment of a Human iPSC- and Nanofiber-Based Microphysiological Blood-Brain Barrier System" (2018). Chemical and Biomolecular Engineering -- All Faculty Papers. 73.

https://digitalcommons.unl.edu/chemengall/73

This Article is brought to you for free and open access by the Chemical and Biomolecular Engineering, Department of at DigitalCommons@University of Nebraska - Lincoln. It has been accepted for inclusion in Chemical and Biomolecular Engineering -- All Faculty Papers by an authorized administrator of DigitalCommons@University of Nebraska - Lincoln. 


\section{Authors}

Dianjun Qi, Shaohua Wu, Haishuang Lin, Mitchell A. Kuss, Yuguo Lei, Alexey Krasnoslobodtsev, Shaheen Ahmed, Chi Zhang, Hyung Joon Kim, Peng Jiang, and Bin Duan 
Published in final edited form as:

ACS Appl Mater Interfaces. 2018 July 05; 10(26): 21825-21835. doi:10.1021/acsami.8b03962.

\title{
Establishment of a Human iPSC- and Nanofiber-Based Microphysiological Blood-Brain Barrier System
}

\author{
Dianjun Qi ${ }^{\dagger, \ddagger, \perp}$, Shaohua Wu ${ }^{\ddagger, \S}$, Haishuang Lin", Mitchell A. Kuss ${ }^{\ddagger, \perp}$, Yuguo Lei ${ }^{\ddagger, \|, i D}$, Alexey \\ Krasnoslobodtsev\#, Shaheen Ahmed", Chi Zhangף", Hyung Joon Kim ${ }^{\ddagger}, \nabla$, Peng Jiang ${ }^{\star}, \circ$, and \\ Bin Duan ${ }^{*}, \neq, \perp, \diamond$, iD \\ tDepartment of General Practice, The First Affiliated Hospital of China Medical University, \\ Shenyang, Liaoning 110001, China \\ ¥Mary \& Dick Holland Regenerative Medicine Program, University of Nebraska Medical Center, \\ Omaha, Nebraska 68198, United States \\ ${ }^{\perp}$ Division of Cardiology, Department of Internal Medicine, University of Nebraska Medical Center, \\ Omaha, Nebraska 68198, United States \\ IDepartment of Radiation Oncology, University of Nebraska Medical Center, Omaha, Nebraska \\ 68198, United States \\ ${ }^{\nabla}$ Department of Psychiatry, University of Nebraska Medical Center, Omaha, Nebraska 68198, \\ United States \\ -Department of Surgery, University of Nebraska Medical Center, Omaha, Nebraska 68198, \\ United States \\ §College of Textiles \& Clothing, Qingdao University, Qingdao 266071, China \\ "Department of Chemical and Biomolecular Engineering, University of Nebraska-Lincoln, \\ Lincoln, Nebraska 68588, United States \\ \#Department of Physics, University of Nebraska at Omaha, Omaha, Nebraska 68182, United \\ States \\ 'Department of Cell Biology and Neuroscience, Rutgers University, Piscataway, New Jersey \\ 08854, United States
}

\section{Abstract}

*Corresponding Authors. peng.jiang@ rutgers.edu. Phone: +1 8484452805 (P.J.). bin.duan@unmc.edu. Phone: +1 4025599637 (B.D.).

ORCID

Yuguo Lei: 0000-0002-7682-6912

Bin Duan: 0000-0002-5647-3793

ASSOCIATED CONTENT

Supporting Information

The Supporting Information is available free of charge on the ACS Publications website at DOI: 10.1021/acsami.8b03962.

Demonstration of the capacity of the 3D-printed holder (AVI)

Human iPSC-ECs expressing CD31 and CD144 and the permeability coefficient of sodium fluorescein (PDF)

The authors declare no competing financial interest. 
The blood-brain barrier (BBB) is an active and complex diffusion barrier that separates the circulating blood from the brain and extracellular fluid, regulates nutrient transportation, and provides protection against various toxic compounds and pathogens. Creating an in vitro microphysiological BBB system, particularly with relevant human cell types, will significantly facilitate the research of neuropharmaceutical drug delivery, screening, and transport, as well as improve our understanding of pathologies that are due to BBB damage. Currently, most of the in vitro BBB models are generated by culturing rodent astrocytes and endothelial cells, using commercially available transwell membranes. Those membranes are made of plastic biopolymers that are nonbiodegradable, porous, and stiff. In addition, distinct from rodent astrocytes, human astrocytes possess unique cell complexity and physiology, which are among the few characteristics that differentiate human brains from rodent brains. In this study, we established a novel human BBB microphysiologocal system, consisting of a three-dimensionally printed holder with a electrospun poly(lactic- $c o$-glycolic) acid (PLGA) nanofibrous mesh, a bilayer coculture of human astrocytes, and endothelial cells, derived from human induced pluripotent stem cells (hiPSCs), on the electrospun PLGA mesh. This human BBB model achieved significant barrier integrity with tight junction protein expression, an effective permeability to sodium fluorescein, and higher transendothelial electrical resistance (TEER) comparing to electrospun mesh-based counterparts. Moreover, the coculture of hiPSC-derived astrocytes and endothielial cells promoted the tight junction protein expression and the TEER value. We further verified the barrier functions of our BBB model with antibrain tumor drugs (paclitaxel and bortezomib) and a neurotoxic peptide (amyloid $\beta 1-42$ ). The human microphysiological system generated in this study will potentially provide a new, powerful tool for research on human BBB physiology and pathology.

\section{Graphical abstract}

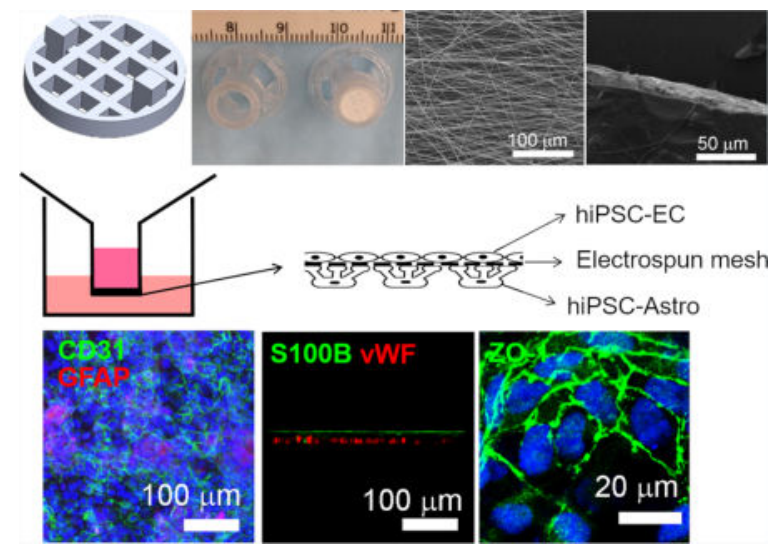

\section{Keywords}

electrospinning; 3D printing; human induced pluripotent stem cells; transepithelial electrical resistance; drug screening

\section{INTRODUCTION}

The blood-brain barrier (BBB) is a highly selective, semipermeable membrane barrier that strictly regulates molecular exchange and separates the circulating blood from the brain. ${ }^{1}$ 
BBB is mainly composed of endothelial cells (ECs), pericytes, astrocytes, and basal membrane (BM) (i.e., a thin layer of fibrous extracellular matrix $[\mathrm{ECM}]) .{ }^{2,3}$ ECs provide tight and adherent cellular junctions and form a diffusion barrier, which strongly regulates the penetration of blood-borne molecules into the brain. ${ }^{4,5}$ Astrocytes are essential for the formation and maintenance of the BBB by leading to closer tight junctions, secreting growth factors and cytokines, and providing the cellular link to the neurons. ${ }^{1,6}$ Apart from the cellular components, BM is another vital component of the BBB, playing both structural and modulatory roles. ${ }^{7} \mathrm{BM}$ and its ECM proteins provide physical support and anchor points for ECs and astrocytes and regulate cellular interaction and signaling. ${ }^{8,9}$

In the past few decades, many in vitro BBB models have been developed to imitate the human BBB because animal models do not always reflect the biology of the BBB-related human diseases. ${ }^{10,11}$ Currently, the basic structure of the BBB in vitro model includes a transwell membrane insert and seeded cells. ${ }^{10,12}$ Primary brain ECs isolated from human brain tissue were monocultured or co/tricultured with pericytes on one side of the insert membrane and astrocytes (sometimes with neurons) on the other side. ${ }^{13-16}$ One trend is the utilization of human pluripotent or adult stem cells instead of primary cells or cells immortalized by the introduction of genes that deregulate the cell cycle because of the limitations that primary cells have, such as low availability and reproducibility, and that immortalized human cells are unable to form strong barrier properties because of the loss of important phenotypes, such as tight junctions. ${ }^{17-19}$ Human pluripotent stem cells, especially human induced pluripotent stem cells (hiPSCs), are a promising stem cell source and have enormous potential for the development of human BBB in vitro models. ${ }^{19,20}$ Human iPSCbased BBB models have been generated, but many studies used a coculture with mixed species, such as rat astrocytes. ${ }^{20,21}$ The human brain is far more complex than the rodent brain, with the complexity of astrocytes being among the key characteristics that differentiate human brains from rodent brains. ${ }^{22,23}$ It is thus imperative to develop robust and reproducible BBB models with a combination of human ECs and astrocytes and even with human pericytes and neurons. ${ }^{16}$ In addition, an hiPSC-based BBB model will be beneficial and will provide a possible strategy for personalized drug screening for BBBrelated diseases.

Another major limitation of the current in vitro BBB model is the use of plastic and porous transwell membrane inserts, which are standard, commercially available membranes made from polyethylene terephthalate (PET), ${ }^{24}$ polycarbonate, ${ }^{25}$ or polytetrafluoroethylene. ${ }^{26}$ These materials cannot fully mimic human BM because they are stiff, less porous, and lack a three-dimensional (3D) structure comparable to native tissue. ${ }^{27,28}$ Most importantly, these materials cannot be remodeled by cells and lack cell-material interactions. The BBB is dynamically maintained and regulated by a complex cross talk between ECs and cells from the neurovascular unit. ${ }^{29}$ Therefore, 3D substrates, which are biodegradable and able to support cell remodeling and EC-astrocyte interaction, are more appropriate for in vitro BBB model development. Recently, several groups have implemented electrospinning, which is a versatile technique used to fabricate scaffolds composed of a 3D, porous, and nano/ microfibrous matrix, to mimic BM structure in BBB models. ${ }^{30-32}$ However, the transendothelial electrical resistance (TEER), which is a sensitive and reliable indicator of the integrity of the tight junction dynamics in $\mathrm{BBB}$, was relatively low, probably due to the 
poor integration of the electrospun meshes with the transwell insert and the chosen cell types.

In this study, we designed and fabricated a 3D nanofibrous BM-like matrix by combining electrospinning and 3D printing techniques and further developed an in vitro BBB model by coculture of hiPSC-derived ECs and astrocytes (hiPSC-ECs, hiPSC-Astro). We systematically characterized the properties of this BBB model and further verified its barrier functions to antiglioblastoma (GBM) drugs and a neurotoxic peptide.

\section{EXPERIMENTAL SECTION}

\subsection{Preparation of a 3D Nanofibrous Matrix on the 3D-Printed Holder}

The holder with diameter of $7 \mathrm{~mm}$, thickness of $1 \mathrm{~mm}$, and pore size of $1 \mathrm{~mm} \times 1 \mathrm{~mm}$ (Figure 1A) was designed and 3D-printed by using a digital light processing-based 3D printer (Vida, EnvisionTec) and a biocompatible light curing methacrylic-/acrylic-resin (EnvisionTec, with components of urethandimethacrylate, neopentyglcol-diacrylate, and phosphinoxide). Two handles were designed to facilitate the handling by tweezers. The holder can perfectly fit into the commercially available transwell insert (24-well, Corning), with the removal of the inside PET membrane. Then, the 3D-printed holders were mounted onto the grounded flat surface, which was covered with aluminum foil, to collect the electrospun poly lactic-co-glycolic acid (PLGA) fibers (Figure 1B). PLGA (82:18; L-lactide/ glycolide, Corbion Purac Biomaterials) was dissolved in 1,1,1,3,3,3-hexafluoroisopropanol (HFIP) to prepare a $10 \%$ solution for electrospinning. Then, $10 \mathrm{~mL}$ of the solution was loaded into a plastic syringe equipped with a 23 gauge needle made of stainless steel. The needle was connected to a high-voltage supply (ES30P-5W, Gamma High Voltage Research Inc.) $)^{33}$ and positive voltage was applied to the reservoir at approximately $12 \mathrm{kV}$. The solution was continuously supplied using a syringe pump (Model 78-01001, Fisher Scientific) at a rate of $0.8 \mathrm{~mL} / \mathrm{h}$. The distance between the needle tip and the collector was $15 \mathrm{~cm}$. Figure 1C shows the 3D-printed holders with and without the electrospun PLGA mesh. The holders fit well into the transwell insert (Figure 1D).

\subsection{Scanning Electron Microscopy Observation}

The morphology of PLGA nanofibers was characterized using scanning electron microscopy (SEM) (FEI Quanta 200, Japan). The electrospun PLGA mesh was peeled from the 3Dprinted holder and was sputter coated with gold under a nitrogen atmosphere and imaged using $12.5 \mathrm{kV}$ accelerating voltage. To image and measure the thickness, the peeled PLGA mesh was sandwiched between two holders and was sectioned by using a cryotome to expose the mesh in the pore area. The diameter of the fibers and the thickness of the mesh were measured by using Image J software. To observe the morphology of iPSC-ECs on the PLGA mesh, samples were fixed by $4 \%$ (v/v) paraformaldehyde (PFA) for $4 \mathrm{~h}$ and then dehydrated, critical point-dried, and gold-sputtered for SEM imaging.

\subsection{Characterization of Mechanical Properties}

Uniaxial tensile tests were performed using a Shakopee MN55379 tester with a custom grip gap of $1 \mathrm{~cm}$. The 3D-printed holders were removed from electrospun PLGA meshes and the 
meshes were cut into pieces (10 $\mathrm{mm}$ in width and $30 \mathrm{~mm}$ in length) with the holder area in the center (Figure 2D). The thickness of the scaffolds was measured with an electronic digital clipper. A displacement of $1 \mathrm{~mm} / \mathrm{min}$ was applied to each specimen and the data were collected until a break occurred. The Young's modulus, breaking strength, and breaking strain were measured and calculated.

The stiffness of the PLGA meshes was characterized via atomic force microscopy (AFM) nanoindentation measurements, using a Force Robot 300 instrument (JPK Instruments, Berlin, Germany). The meshes were affixed to microscope glass slides and transferred to an atomic force microscope chamber for measurements. All of the measurements were taken at room temperature. A silicon-nitride AFM probe-PT.GS (Novascan Technologies, Inc, Boone, IA), with a glass spherical particle attached, was used for indentation measurements. The probe had a deflection sensitivity of $24.6 \mathrm{~nm} / \mathrm{V}$, which was calibrated against a hard (mica) surface. The spring constant of the cantilever was obtained using a thermal method and amounted to $46.3 \mathrm{mN} / \mathrm{m}$. Samples were visualized with a built-in charge-coupled device camera in the atomic force microscope head. Different sections (pore region vs strut region) of the electrospun mesh were identified based on their contrast. The indentation measurements were performed on a $10 \times 10 \mu \mathrm{m}$ area using a $20 \times 20$ grid. Such a large area allowed us to account for spatial heterogeneity of the sample by statistically averaging the measured points on the grid. The mechanical properties of each point on the grid were probed by one indentation cycle with loading/unloading curves. During loading, the probe was pushed into the mesh to a $5 \mathrm{nN}$ loading force with a speed of $1 \mu \mathrm{m} / \mathrm{s}$, which was followed by an unloading curve with the same speed. Loading force $(5 \mathrm{nN})$ corresponds to $\sim 108 \mathrm{~nm}$ of indentation depth, which was chosen to be small enough to be compared to the thickness of the meshes to avoid any influence of the underlying surface. Collected curves were analyzed with the JPK Data Processing software package. The sample stiffness (Young's modulus) was obtained by fitting the loading curves to a Hertz-Sneddon model using spherical tip geometry. The fitting was done with a Poisson ratio of 0.50 and calibrated parameters of the tip geometry, namely a tip radius of $5 \mu \mathrm{m}$.

\subsection{Cell Culture and Seeding}

Two healthy hiPSC lines were reprogrammed from fibroblasts obtained from healthy individuals, as described in our previous study. ${ }^{34}$ An embryoid body-based differentiation procedure was used for the differentiation of these hiPSCs to neural progenitor cells (NPCs) (hiPSC-NPCs) and then astrocytes (hiPSC-Astro) and neurons. ${ }^{34-37}$ The hiPSC-NPCs were cultured and expanded in the growth medium, containing a mixture (1:1) of Dulbecco's modified Eagle medium (DMEM)/F12 and Neurobasal medium, supplemented with $1 \times \mathrm{N} 2$, $1 \times \mathrm{B} 27,20 \mathrm{ng} / \mathrm{mL}$ basic fibroblastic growth factor (bFGF), and $1 \%$ Pen/Strep at $37{ }^{\circ} \mathrm{C}$ in a $5 \% \mathrm{CO}_{2}$ atmosphere. The hiPSC-NPCs were harvested using TrypLE (Gibco), resuspended in growth medium, and seeded $\left(5 \times 10^{4}\right.$ cells per well) in 24-well plates with a Matrigel coating. Y-27632 (Tocris, $10 \mu \mathrm{M}$, a ROCK inhibitor) was added to the medium on the first day of seeding. To induce astroglial differentiation, the hiPSC-NPCs were then cultured in a medium containing DMEM/F12 (HyClone), $10 \mathrm{ng} / \mathrm{mL}$ bone morphogenetic protein (BMP)-4 (PeproTech), 1× N2 (Thermo Fisher Scientific), 1× B27 (Thermo Fisher Scientific), $20 \mathrm{ng} / \mathrm{mL}$ bFGF (Peprotech), and 1\% Pen/Strep (Invitrogen). To induce neuronal 
differentiation, the hiPSC-NPCs were cultured in a medium consisting of 50\% DMEM/F12, $50 \%$ Neurobasal medium, 1\% N2, 2\% B27, $10 \mu \mathrm{M}$ cAMP (Sigma), $200 \mathrm{nM}$ Ascorbic Acid (Sigma), $10 \mathrm{ng} / \mathrm{mL}$ brain-derived neurotrophic factor (Peprotech), $10 \mathrm{ng} / \mathrm{mL}$ glial cell linederived neurotrophic factor (Peprotech), and $1 \% \mathrm{Pen} / \mathrm{Strep}$. Astroglial and neuronal differentiation was conducted for $2-3$ weeks at $37{ }^{\circ} \mathrm{C}$ in a $5 \% \mathrm{CO}_{2}$ atmosphere.

For EC differentiation, hiPSCs were dissociated with Accutase and plated on Matrigel at a density of 40000 cells $/ \mathrm{cm}^{2}$ in E8 with $10 \mu \mathrm{M} \mathrm{Y-27632.} \mathrm{After} 24 \mathrm{~h}$, the medium was replaced with differentiation medium, consisting of a 1:1 mixture of DMEM/F12 with GlutaMAX and Neurobasal media, supplemented with $1 \times \mathrm{N} 2$ and $1 \times \mathrm{B} 27$ with $8 \mu \mathrm{M}$ CHIR99021 (LC laboratories) and $25 \mathrm{ng} / \mathrm{mL}$ BMP-4. After 3 days, the differentiation medium was replaced by EC induction medium, consisting of StemPro-34 SFM medium (Life Technologies), supplemented with $200 \mathrm{ng} / \mathrm{mL}$ VEGFA (PeproTech) and $2 \mu \mathrm{M}$ Forskolin (Sigma). The induction medium was changed after 1 day. On day 6 of differentiation, the hiPSC-ECs were replated on human fibronectin (Sigma)-coated dishes at a density of 25000 cells $/ \mathrm{cm}^{2}$ in EC growth medium 2 (EGM-2, Lonza). The derived hiPSCECs were positive to CD31 and CD144 (Figure S1). The hiPSC-derived cells were harvested using the dissociation reagent TrypLE, centrifuged, and resuspended in DMEM/F12 basal medium or EGM-2. Then, the cells were surface-seeded onto the Matrigel (Corning)-coated electrospun PLGA matrix on the holder. Each insert was seeded with $5 \times 10^{5}$ cells, which were resuspended in $20 \mu \mathrm{L}$ of medium. After incubation in the incubator for $3 \mathrm{~h}$ to allow cell attachment, the corresponding medium was added. The medium was replaced every second day before seeding and every day after seeding. For the coculture of hiPSC-ECs and hiPSCAstro, the hiPSC-Astro were first seeded on the bottom side of the electrospun PLGA matrix on the holder inserted into the traswell. One day later, hiPSC-ECs were seeded on the top side of the electrospun PLGA mesh. The upper chamber was filled with EGM-2, and the lower chamber was filled with hiPSC-Astro medium. The cell culture plates were incubated at $37{ }^{\circ} \mathrm{C}$ in a $5 \% \mathrm{CO}_{2}$ incubator for up to 7 days.

U87MG GBM cells (ATCC) were cultured in DMEM/F12, with 10\% (v/v) fetal bovine serum (Gibco) and $1 \%$ Pen/Strep at $37{ }^{\circ} \mathrm{C}$ in a $5 \% \mathrm{CO}_{2}$ atmosphere. Each well of the 24well plate was seeded with $1 \times 10^{4}$ cells after harvesting with trypsin, centrifugation, and resuspension in the growth medium. The medium was replaced every other day.

For the triculture of hiPSC-ECs, hiPSC-Astro, and hiPSC-NPCs or U87MG, hiPSC-NPCs or U87MG were cultured in a 24-well plate, in the lower chamber, with neuronal differentiation medium or astroglial differentiation medium, respectively. The BBB model with hiPSC-ECs and hiPSC-Astro was cultured in the transwell insert with the PLGA mesh and 3D-printed holder. The upper chamber was filled with EGM-2.

\subsection{Cell Viability}

The viability of cells was determined using a Live/Dead assay (Invitrogen) 3 days after seeding, as previously described, ${ }^{38}$ and fluorescence images were obtained using confocal laser scanning microscopy (LSM 710, Carl Zeiss). 


\subsection{Immunofluorescence Staining}

For immunofluorescence (IF) staining, samples were fixed in 4\% (v/v) PFA, permeabilized in $0.2 \%$ Triton $\mathrm{X}-100$ for $10 \mathrm{~min}$, and then blocked with $1 \%$ bovine serum albumin overnight at $4{ }^{\circ} \mathrm{C}$. The samples were incubated with primary antibodies to CD31 (1:100, Invitrogen), von Willebrand Factor (vWF) (1:100, Sigma), glial fibrillary acidic protein (GFAP) (1:200, Sigma), S100B (1:500, Cell Signaling), vimentin (1:100, Sigma), Caspase-3 (1:100, Cell Signaling), Tuj-1 (1:100, Cell Signaling), and zonula occluden-1 (ZO-1, 1:100, Thermo Fisher Scientific) overnight at $4{ }^{\circ} \mathrm{C}$. Secondary fluorescent antibodies $(1: 100)$ were incubated for $2 \mathrm{~h}$ and nuclear counterstaining (via Draq 5, 1:1000, Biostatus) was performed for 30 minutes at room temperature. Then, the samples were imaged with a Zeiss 710 confocal laser scanning microscope.

\subsection{TEER Analysis}

TEER is a noninvasive way to measure the electrical resistance across a cellular monolayer or cell coculture. The TEER values of a blank mesh (without any cells), a mesh with hiPSCAstro, and BBB tissue (with both hiPSC-ECs and hiPSC-Astro) were measured by using a Millicell electrical resistance apparatus (Endohm-6 and EVOM, World Precision Instruments). The average TEER value was monitored and analyzed for 7 days while being performed in triplicate. The TEER value was calculated as follows:

$$
\text { TEER value }\left(\Omega \cdot \mathrm{cm}^{2}\right)=\text { TEER }(\Omega) \times \text { surface area }\left(0.385 \mathrm{~cm}^{2}\right)
$$

\subsection{Sodium Fluorescein Permeability Studies}

Sodium fluorescein permeability studies were conducted after the TEER reached maximum values. The engineered BBB tissues were washed with Dulbecco's phosphate-buffered saline (DPBS) (Gibco), and then, $200 \mathrm{~mL}$ of sodium fluorescein (Sigma), diluted in DPBS, was loaded into the upper chambers. DPBS $(1000 \mu \mathrm{L})$, without sodium fluorescein, was loaded into the lower chambers. The whole setup was incubated in the incubator for $30 \mathrm{~min}$. After incubation, the DPBS in the lower chamber was collected and the concentration of sodium fluorescein was determined using a microplate reader $(\operatorname{Ex}(\lambda) 485 \mathrm{~nm}, \operatorname{Em}(\lambda) 535$ $\mathrm{nm}$, BioTek). The permeability coefficient $(\mathrm{cm} / \mathrm{s})$ was calculated as follows

$$
\text { Permeability coefficient }=\frac{V_{\mathrm{Ab}} \times C_{\mathrm{Ab}}}{S \times C \times t}
$$

$V_{\mathrm{Ab}}$ is the volume of the lower chamber, $C_{\mathrm{Ab}}$ is the concentration of sodium fluorescein in the lower chamber, $S$ is the surface area of the filter, $C$ is the concentration of sodium fluorescein, and $t$ is the incubation time.

\subsection{Toxicity Treatment}

We examined the barrier function of the engineered BBB model by the addition of toxic drugs and the evaluation of the subsequent cell response. We tricultured BBB tissues with U87MG or hiPSC-NPCs and added an anti-GBM drug or human $\beta$-amyloid 1-42 (A $\beta$, Genscript) in the upper chamber, with the accommodation of the BBB tissue. We used an 
empty mesh (without cell culture) as a positive control and used the groups without the addition of drugs as a negative control. For the toxicity treatment, U87MG cells were cultured at a density of $1 \times 10^{4}$ cells/well in 24 wells at $37{ }^{\circ} \mathrm{C}$. Then, a paclitaxel (PTX) (Selleckchem, $1 \mu \mathrm{g} / \mathrm{mL}$, or $2 \mu \mathrm{g} / \mathrm{mL}$ ) or bortezomib (BTZ) (Selleckchem, $4 \mu \mathrm{g} / \mathrm{mL}$, or 8 $\mu \mathrm{g} / \mathrm{mL}$ ) solution was added to the upper chamber with BBB tissue and tricultured with U87MG for $24 \mathrm{~h}$. For the neuronal toxicity treatment, human A $\beta$ was dissolved in PBS (100 $\mu \mathrm{g} / \mathrm{mL}$ ) and then incubated at $37^{\circ} \mathrm{C}$ for 4 days to initiate aggregate formulation. ${ }^{39}$ Human iPSC-NPCs were subjected to neuronal differentiation for 14 days and tricultured with BBB tissue. Then, the aggregated $\mathrm{A} \beta(4 \mu \mathrm{g} / \mathrm{mL})$ was added for $48 \mathrm{~h}$ culture.

\subsection{Lactate Dehydrogenase Assay}

Cytotoxicity was estimated by determining lactate dehydrogenase (LDH) released into the culture medium. Supernatants and lysates of U87MG cells (with or without PTX and BTZ) and hiPSC-NPC-induced neuron cells (with or without A $\beta$ ) were collected. An LDH-based CytoTox 96 Assay (Promega) was performed according to the manufacturer instructions. The percentage of cytotoxicity $(\%)$ was calculated as follows

$$
\text { Percentage of cytotoxicity }(\%)=\frac{\mathrm{LDH} \text { activity supernatant }\left(\mathrm{OD}_{490}\right)}{\mathrm{LDH} \text { activity cell lysate }\left(\mathrm{OD}_{490}\right)} \times 100
$$

\subsection{3-(4,5-Dimethylthiazol-2-yl)-2,5-diphenyltetrazolium Bromide Assay}

We also evaluated U87MG cell viability with PTZ and BTZ treatments, with or without engineered BBB tissue, by using an 3-(4,5-dimethylthiazol-2-yl)-2,5-diphenyltetrazolium bromide (MTT) assay, as described previously. ${ }^{40}$ Briefly, $25 \mu \mathrm{L}$ of MTT solution (10 $\mathrm{mg} / \mathrm{mL}$ ) was added into each well and incubated for $4 \mathrm{~h}$. Then, $500 \mu \mathrm{L}$ of dimethyl sulfoxide (Sigma, USA) was added to dissolve the formazan crystals after the medium was removed. The absorbance at $540 \mathrm{~nm}$ was measured using the microplate reader.

\subsection{Statistical Analysis}

All quantitative data is expressed as the mean \pm standard deviation. Statistical analysis was performed using analysis of variance with Scheffé post-hoc tests. $P$ values $<0.05$ were considered statistically significant.

\section{RESULTS}

\subsection{Fabrication and Characterization of the Nanofibrous PLGA Mesh on the 3D-Printed Holder}

We first 3D-printed a holder that can perfectly fit into the 24-well transwell frame (Video 1). The struts were designed to hold the electrospun fibers and to prevent leaking due to the pressure generated in the transwell. The pores on the holders guarantee the permeability of the whole device. Then, a thin layer of a nanofibrous PLGA mesh was electrospun on the surface of the holders (Figure 1B). Figure 1C shows the 3D-printed holder with (left) and without (right) the electrospun PLGA mesh. The electrospun PLGA mesh on the holder was inserted into the 24-well transwell, after removing the transwell membrane (Figure 1D). 
As shown in SEM micrographs in Figure 2A,B, a fibrous morphology of the electrospun PLGA mesh was observed. The PLGA nanofibers in the pore area were thinner than those in the strut area. The diameter of the PLGA nanofibers was around $800 \mathrm{~nm}$, and the thickness of the electrospun PLGA mesh in the pore area was around $30 \mu \mathrm{m}$ (Figure 2C). The thinner thickness facilitated more cell-cell contact between hiPSC-ECs and hiPSC-Astro, which may improve BBB barrier integrity. ${ }^{41}$

We further peeled the PLGA mesh from the holder and conducted a tensile test and nanoindentation to measure the bulk Young's modulus (Figure 2D) and local stiffness, respectively. The typical stress-strain curve was shown in Figure 2E. The Young's modulus of the PLGA mesh was $53.8 \pm 4.5 \mathrm{MPa}$, which is a little bit higher than the in vivo human BBB (an estimated Young's modulus around 8-10 kPa) but much smaller than the commercial PET transwell membrane ( $2 \mathrm{GPa}) .{ }^{32}$ The nanoindentation results showed that the stiffness in the pore area was significantly lower than that in the strut area (Figure 2F). This is probably due to the thickness difference between the two areas. Taken together, we generated an electrospun PLGA mesh onto a 3D-printed holder that fits into the transwell frame. The nanofibrous PLGA mesh has a thin thickness, sufficient mechanical properties, and adequate flexibility.

\subsection{Generation of the hiPSC-Based BBB Model}

To create the BBB model with hiPSC-derived cells, we first seeded hiPSC-ECs and hiPSCAstro separately onto the PLGA meshes. As shown in Figure 3A, both the hiPSC-ECs and hiPSC-Astro had high cell viability on the PLGA meshes. After 3 day culture, IF staining showed that a large number of hiPSC-ECs and hiPSC-Astro spread over the surface of the electrospun mesh (Figure 3B). Human iPSC-ECs were subconfluent because of the large seeding density and were positive for CD31 and vWF expression, showing a well-organized and continuous cell-cell interaction with very few gaps (Figure 3B). Human iPSC-Astro were less confluent and were positive for the astrocytes marker, that is, GFAP and S100B (Figure 3C).

A coculture of hiPSC-ECs and hiPSC-Astro on the electrospun PLGA mesh was achieved by seeding the two cell types on the two opposite sides of the PLGA mesh as shown in Figure 4A. Figure 4B shows confocal images of cocultured cells on the PLGA mesh. After 3 day coculture, the BBB tissues showed positive expression of the astrocyte markers GFAP and S100B, EC junction marker CD31, and glycoprotein vWF. Volume-rendered side views clearly showed two cell layers with the electrospun meshes sandwiched between (Figure 4B). Importantly, hiPSC-ECs in the coculture system were positive to ZO-1 (Figure 4C), which is one of the major tight junction proteins between brain ECs. ${ }^{42}$ The hiPSC-ECs showed an extensive spreading morphology on the PLGA mesh and had close interactions with the PLGA nanofibers (Figure 4D). Notably, many hiPSC-ECs had cell-cell interaction and junctions. It seemed that they were not totally confluent and there was still some space uncovered by the cells, but it is possible that cells had interaction under the fibrous scaffold surface because many cells penetrated the fibers. We further characterized the physical properties, including TEER values and permeability coefficient, of the BBB model. As expected, the empty mesh, without cells, and hiPSC-Astro alone had low TEER values 
(Figure 4E). The addition of hiPSC-ECs significantly increased TEER, and the TEER also dynamically changed with culture time. The TEER values significantly increased from 119.0 $\pm 15.8 \Omega \cdot \mathrm{cm}^{2}$ at day 1 to $232.8 \pm 33.1 \Omega \cdot \mathrm{cm}^{2}$ at day 3 , indicating tightening of hiPSC-EC cell-to-cell contacts, and then gradually fell back to $181.3 \pm 17.1 \Omega \cdot \mathrm{cm}^{2}$ at day 7. A similar trend of TEER value change has been reported in other transwell-based BBB models, using both iPSC-based cells and primary cells. ${ }^{21,43}$ The permeability of our in vitro BBB model to sodium fluorescein was investigated to assess barrier integrity at the third day, which had the peak TEER value, after coculture. As shown in Figure 4F, the permeability coefficient of our BBB model was $2.6 \pm 0.4 \times 10^{-6} \mathrm{~cm} / \mathrm{s}$, which was significantly lower than the empty counterparts $(80.0 \pm 8.0 \mathrm{~cm} / \mathrm{s})$. In addition, the permeability coefficient did not significantly change over time from $30 \mathrm{~min}$ to $3 \mathrm{~h}$ (Figure S2).

\subsection{Barrier Effect of the BBB Model on Anti-GBM Drugs}

We evaluated the barrier functions of the hiPSC- and PLGA mesh-based BBB model to block brain cancer drugs. In this study, we used PTX and BTZ as model drugs, which are widely used as anticancer drugs to treat primary and metastatic brain cancer. ${ }^{44,45}$ Both PTX and BTZ have limited penetration capacities through the BBB. ${ }^{46,47}$ We thus conducted a triculture BBB model consisting of hiPSC-ECs and hiPSC-Astro with U87MG cells, as shown in Figure 5A. We then added PTX or BTZ and evaluated the U87MG response and TEER change after 1 day culture. Under a light microscope, U87MG cells in the control group, without the addition of anti-GBM drugs, showed a normal spreading morphology (Figure 5B). In the BBB group with a lower dose of PTX $(1 \mu \mathrm{g} / \mathrm{mL})$, U87MG cells had a slightly round-up morphology, whereas in the empty mesh group without cells, U87MG cells had fewer numbers, smaller size, and a much rounder morphology. For IF staining, U87MG cells were positive to vimentin, and more apoptotic cells were positive for active Caspase- 3 in the empty mesh group. In contrast, less active Caspase-3 positive cells were observed in the control and BBB groups. With the addition of BTZ $(4 \mu \mathrm{g} / \mathrm{mL})$, the cell number decreased, and the active Caspase- 3 positive cell number increased. This was similar to the effect of the addition of PTX (Figure 5B), but the U87MG cells acquired a spindlelike morphology, especially in the empty mesh group. A similar observation was also reported by other researchers. ${ }^{48}$ This is probably because BTZ activates autophagy of subconfluent U87MG cells, which are subject to morphological and ultrastructural changes.

${ }^{48}$ For the LDH cytotoxicity assay, the percentage of cytotoxicity of U87MG cells in the empty mesh group was significantly higher than those in the control group and BBB group (Figure 5C), but there was no obvious difference between the control group and BBB group. Similarly, MTT results showed that U87MG cell viability statistically decreased with the addition of PTX and BTZ in the empty mesh group, with very limited barrier function (Figure 5D). The U87MG cells in the control and BBB groups had comparable metabolic activity. We further evaluated the TEER value changes after the addition of PTX and BTZ and also assessed the change with anti-GBM drug doses (Figure 5E). The TEER values just slightly decreased with a lower dose, but a significant decrease of the TEER values was observed with a higher dose of anti-GBM drugs. The dose-dependent decrease of TEER values indicated that both PTX and BTZ treatments with high doses compromised the BBB integrity. 


\subsection{Barrier Effect of the BBB Model on A $\beta$}

Dysfunction of the BBB is involved in the pathogenesis of several neurological diseases, including brain trauma, multiple sclerosis, and Alzheimer's disease (AD). ${ }^{49}$ For example, $\mathrm{AD}$ brains are highly associated with leakages of blood-derived molecules, BBB breakdown, and neurovascular unit dysregulation. ${ }^{50,51}$ The extracellular plaques of $\mathrm{A} \beta$ and neurofibrillary tangle formation in the brain are two major pathological hallmarks in $\mathrm{AD} .^{52}$ $\mathrm{A} \beta$ is a small peptide ( $4.5 \mathrm{kDa}$ ) that circulates in plasma, cerebrospinal fluid, and brain interstitial fluid. ${ }^{53,54}$ Normally, $\mathrm{A} \beta$ clearance and degradation are regulated by several mechanisms, such as $\mathrm{A} \beta$ protease degradation, low-density lipoprotein receptor-related protein 1 binding, the efflux by transport of $\mathrm{A} \beta$ across the $\mathrm{BBB}$ into the blood circulation, and the uptake and phagocytosis of by glia cells. ${ }^{53,55,56}$ To verify the $\mathrm{A} \beta$ clearance capacity of the BBB model, we tricultured and engineered the BBB model consisting of hiPSC-ECs and hiPSC-Astro with hiPSC-NPCs (Figure 6A). The hiPSC-NPCs were induced for neuronal differentiation for 14 days before triculture. After 14 day neuronal differentiation, hiPSC-NPCs were positive for Tuj-1 and the axons were clearly observed (Figure 6B, first panel). Then, soluble oligomeric $\mathrm{A} \beta$ was added into the transwell insert with engineered $\mathrm{BBB}$. After 2 day culture, $\mathrm{A} \beta$ aggregates were clearly observed in the empty mesh group but not in the control and BBB groups (Figure 6B). The human neurons differentiated from hiPSC-NPCs showed significantly higher cytotoxicity with $\mathrm{A} \beta$ aggregates in the empty mesh group, and there was no obvious difference between the control and BBB groups (Figure 6C).

\section{DISCUSSION}

In vitro BBB models are important tools to develop and evaluate novel neuropharmaceuticals and to study the fundamental and pathological mechanisms of BBBrelated neurological diseases. ${ }^{19,57}$ Current in vitro BBB models are usually based on commercially available plastic and porous transwell membranes. In this study, we designed and 3D-printed a holder that can support an electrospun PLGA mesh and can perfectly fit into the transwell insert. The whole device, with coculture of hiPSC-ECs and hiPSC-Astro, served as a BBB model. The nanofibrous PLGA mesh is biodegradable, mechanically robust, and flexible. Therefore, the electrospun PLGA mesh can better mimic the BM in native BBB and enhance cell-cell and cell-BM interactions in the neurovascular unit. A similar approach has also been presented by Bischel et al. ${ }^{55} \mathrm{We}$ implemented the 3D-printed holder to support the PLGA mesh and to disperse the pressure and thus achieved significantly improved TEER values. In addition, we used hiPSCs as the cell resource for creating a reproducible and robust hiPSC-derived BBB model. Compared to other cell sources, the pluripotent nature of hiPSCs allows for the generation of various cells in the neurovascular unit with larger scale, a higher purity, and repeatability. ${ }^{19,56}$

In the current study, we confirmed that hiPSC-ECs were the major contributor of TEER and the coculture of hiPSC-ECs and hiPSC-Astro enhanced the expression of tight junction proteins. Similarly, Yamamizu reported that hiPSC-ECs were endowed with features consistent with brain ECs, including a high expression of nutrient transporters and efflux transporters and a strong barrier function, based on tight junctions. ${ }^{16}$ In addition, hiPSC-ECs 
cocultured with primary rat astrocytes or $\mathrm{C} 6$ rat glioma cells also showed brain EC phenotypes. ${ }^{20,57}$ A hallmark of the BBB is a high TEER because of the tight junctions between ECs to maintain barrier integrity. In the current study, although the TEER value was lower than the native BBB $\left(\sim 1000-2000 \Omega \cdot \mathrm{cm}^{2}\right),{ }^{10,12}$ it is still within the reported range for in vitro BBB models. ${ }^{19,58,59}$ Notably, the TEER values of our system were higher than those of the electrospun mesh-based counterpart ${ }^{32}$ and some reported transwell membrane-based BBB models with primary human brain ECs ${ }^{58,60}$ or hiPSC-derived brain ECs. ${ }^{16}$ For example, the electrospun gelatin-genipin biopapers with coculture of primary human astrocytes and human brain microvascular ECs were reported to have TEER values of 10-30 $\Omega \cdot \mathrm{cm}^{2}{ }^{30,32}$ In addition to the implementation of multiple types of cells from different sources, our system with a 3D-printed holder, electrospun mesh, and transwell frame can provide better sealing and integration. Future work is warranted to modify the PLGA surface to promote tight junction protein expression and maturation of brain ECs. Other neurovascular cell types, such as pericytes, may need to be incorporated to stabilize EC and increase the TEER value.

We verified the barrier function of our BBB model by using two types of molecules: (i) antiGBM drugs, including PTX (mitotic inhibitor) and BTZ (proteasome inhibitor), and (ii) a neurotoxic peptide (i.e., $A \beta 1-42$, one of the most common and the most aggregatable isoform). Because of the presence of BBB, the delivery of therapeutic agents to brain cancers (both primary tumors and metastases) has long been a problematic issue. ${ }^{61,62}$ Both PTX and BTZ have poor penetration across the BBB into brain tumors, mainly because the active efflux transporters (such as $p$-glycoprotein and multidrug resistance proteins) transport those antineoplastic drugs back to the blood stream. ${ }^{46,47,63}$ We demonstrated that our BBB model had positive barrier functions to block PTX and BTZ transportation to work on the GBM cells underneath, which is similar to the limited therapeutic effects of PTX and BTZ on GBM in vivo. ${ }^{64,65}$ Our results also demonstrated that a lower dose of PTX and BTZ had a slight effect on the TEER value of the BBB model, with a short time period of administration, whereas a higher dose significantly affected the BBB integrity. During the $\mathrm{AD}$ progression, $\mathrm{BBB}$ plays an important role in regulating the dynamic balance of $\mathrm{A} \beta$ in the brain. ${ }^{53,66}$ Cerebrovascular dysfunction may impair the clearance of $\mathrm{A} \beta$ from the brain and increase the penetration of peripheral $\mathrm{A} \beta$ into the brain, leading to elevated $\mathrm{A} \beta$ deposition in neurons. ${ }^{67,68}$ In the present study, we found that our BBB model can effectively reduce the penetration of the $\mathrm{A} \beta$ oligomer into the neurons differentiated from hiPSC-NPCs.

Our BBB model, with a nanofibrous matrix and hiPSC-derived neurovascular cells, has great potential to implement patient-specific iPSCs for anti-GBM drug screening and gaining new insights into BBB-related neurological diseases. Although our human BBB model in its current format involves a nanofibrous matrix, which is more similar to native BM compared to plastic transwell membranes, future studies are required to construct a 3D BBB model with a BM-like matrix and all four neurovascular cell populations (i.e., brain ECs, pericytes, astrocytes, and neurons). The combination of 3D printing, electrospinning, and/or other 3D biofabrication techniques will enable us to generate more complex structures to better accommodate the cells. In addition, pericytes have been successfully generated from hiPSCs and hopefully can be employed to further improve the TEER value. ${ }^{16,69}$ 


\section{CONCLUSIONS}

In the current study, we designed and 3D-printed a holder to accommodate an electrospun PLGA mesh and fit into a tranwell insert frame, and we further generated an in vitro human BBB model by bilayer coculture of hiPSC-ECs and hiPSC-Astro. The PLGA nanofibrous mesh had thin thickness, sufficient mechanical properties, adequate flexibility, and supported the growth and phenotypic expression of hiPSC-ECs and hiPSC-Astro. We demonstrated that the BBB model had strong barrier function and normal permeability. The coculture of hiPSC-ECs and hiPSC-Astro promoted tight junction protein expression and TEER value. Our BBB model, with biomimetic in vivo function and integrity, had significant barrier effects on anti-GBM drugs (PTX and BTZ) and the neurotoxic peptide (A $\beta 1-42)$ transportation to GBM cells and hiPSC-NPC-derived neurons. The implementation of hiPSCs to derive neurovascular cells enables us to generate a BBB model that is more similar to human physiology not only due to the cell availability and function but also its potential of being disease-specific and patient-specific. This strategy and model will be useful for the study of intracranial drug delivery and screening and for research on human BBB physiology and pathology.

\section{Supplementary Material}

Refer to Web version on PubMed Central for supplementary material.

\section{Acknowledgments}

This work has been supported by Mary \& Dick Holland Regenerative Medicine Program start-up grant, Mary \& Dick Holland Regenerative Medicine Program pilot project grant, and Nebraska Research Initiative funding to B.D. and grants from the NIH (R21HD091512 and R01NS102382) to P.J. Nebraska Stem Cell Research Project Grant to B.D., Y.L., and H.J.K. We would like to thank Jane DeVasure and Dr. Todd Wyatt for the assistance of TEER measurement. We would like to thank Dr. Linxia Gu and Pengfei Dong for the assistance of tensile tests. We would like to thank Janice A. Taylor and James R. Talaska of the Advanced Microscopy Core Facility at the University of Nebraska Medical Center (UNMC) for providing assistance with confocal microscopy. Support for the UNMC Advanced Microscopy Core Facility was provided by the Nebraska Research Initiative, the Fred and Pamela Buffett Cancer Center Support Grant (P30CA036727), and an Institutional Development Award (IDeA) from the NIGMS of the NIH (P30GM106397). We would also like to thank the Nanoimaging Core Facility at UNMC for providing access to the Force Robot 300 instrument (JPK, Berlin, Germany).

\section{ABBREVIATIONS}

$\begin{array}{ll}\text { iPSCs } & \text { induced pluripotent stem cells } \\ \text { BBB } & \text { blood-brain barrier } \\ \text { PLGA } & \text { poly(lactic-co-glycolic) acid } \\ \text { TEER } & \text { transendothelial electrical resistance } \\ \text { ECs } & \text { endothelial cells } \\ \text { ECM } & \text { extracellular matrix } \\ \text { HFIP } & 1,1,1,3,3,3-\text { hexafluoroisopropanol } \\ \text { PFA } & \text { paraformaldehyde }\end{array}$




$\begin{array}{ll}\text { NPC } & \text { neural progenitor cells } \\ \text { Astro } & \text { astrocytes } \\ \text { LDH } & \text { lactate dehydrogenase } \\ \text { MTT } & \text { 3-(4,5-dimethylthiazol-2-yl)-2,5-diphenyltetrazolium bromide } \\ \text { GBM } & \text { glioblastoma } \\ \text { PTX } & \text { paclitaxel } \\ \text { BTZ } & \text { bortezomib }\end{array}$

\section{References}

1. Abbott NJ, Rönnbäck L, Hansson E. Astrocyte-Endothelial Interactions at the Blood-Brain Barrier. Nat. Rev. Neurosci. 2006; 7:41-53. [PubMed: 16371949]

2. Armulik A, Genové G, Mäe M, Nisancioglu MH, Wallgard E, Niaudet C, He L, Norlin J, Lindblom P, Strittmatter K, Johansson BR, Betsholtz C. Pericytes Regulate the Blood-Brain Barrier. Nature. 2010; 468:557-561. [PubMed: 20944627]

3. Daneman R, Zhou L, Kebede AA, Barres BA. Pericytes Are Required for Blood-Brain Barrier Integrity during Embryogenesis. Nature. 2010; 468:562-566. [PubMed: 20944625]

4. Stamatovic SM, Keep RF, Andjelkovic AV. Brain Endothelial Cell-Cell Junctions: How to "Open" the Blood Brain Barrier. Curr. Neuropharmacol. 2008; 6:179-192. [PubMed: 19506719]

5. Deeken JF, Loscher W. The Blood-Brain Barrier and Cancer: Transporters, Treatment, and Trojan Horses. Clin. Cancer Res. 2007; 13:1663-1674. [PubMed: 17363519]

6. Cabezas R, Ávila M, Gonzalez J, El-Bachá RS, Báez E, García-Segura LM, Coronel JCJ, Capani F, Cardona-Gomez GP, Barreto GE. Astrocytic Modulation of Blood Brain Barrier: Perspectives on Parkinson's Disease. Front. Cell. Neurosci. 2014; 8:211. [PubMed: 25136294]

7. Tajes M, Ramos-Fernández E, Weng-Jiang X, Bosch-Morató M, Guivernau B, Eraso-Pichot A, Salvador B, Fernàndez-Busquets X, Roquer J, Muñoz FJ. The Blood-Brain Barrier: Structure, Function and Therapeutic Approaches to Cross It. Mol. Membr. Biol. 2014; 31:152-167. [PubMed: 25046533]

8. Benarroch EE. Blood-Brain Barrier: Recent Developments and Clinical Correlations. Neurology. 2012; 78:1268-1276. [PubMed: 22508848]

9. Chester AH, , Taylor PM. Molecular Structure and Function of the Tight Junction; Proceedings of an International Conference Dedicated to the Memory of Shoichiro Tsukita; Germany, Berlin. April 25-27, 2008; Annals of the New York Academy of Sciences; 20091346

10. Wolff A, Antfolk M, Brodin B, Tenje M. In Vitro Blood-Brain Barrier Models-An Overview of Established Models and New Microfluidic Approaches. J. Pharm. Sci. 2015; 104:2727-2746. [PubMed: 25630899]

11. Vatine GD, Al-Ahmad A, Barriga BK, Svendsen S, Salim A, Garcia L, Garcia VJ, Ho R, Yucer N, Qian T, Lim RG, Wu J, Thompson LM, Spivia WR, Chen Z, Van Eyk J, Palecek SP, Refetoff S, Shusta EV, Svendsen CN. Modeling Psychomotor Retardation using iPSCs from MCT8-Deficient Patients Indicates a Prominent Role for the Blood-Brain Barrier. Cell Stem Cell. 2017; 20:831843. e5. [PubMed: 28526555]

12. Wilhelm I, Krizbai IA. In Vitro Models of the Blood-Brain Barrier for the Study of Drug Delivery to the Brain. Mol. Pharmaceutics. 2014; 11:1949-1963.

13. Wilhelm I, Fazakas C, Krizbai IA. In Vitro Models of the Blood-Brain Barrier. Acta Neurobiol. Exp. 2011; 71:113-128.

14. Rubin LL, Hall DE, Porter S, Barbu K, Cannon C, Horner HC, Janatpour M, Liaw CW, Manning K, Morales J. A Cell Culture Model of the Blood-Brain Barrier. J. Cell Biol. 1991; 115:17251735. [PubMed: 1661734] 
15. Schroeter ML, Mertsch K, Giese H, Müller S, Sporbert A, Hickel B, Blasig IE. Astrocytes Enhance Radical Defence in Capillary Endothelial Cells Constituting the Blood-Brain Barrier. FEBS Lett. 1999; 449:241-244. [PubMed: 10338140]

16. Yamamizu K, Iwasaki M, Takakubo H, Sakamoto T, Ikuno T, Miyoshi M, Kondo T, Nakao Y, Nakagawa M, Inoue H, Yamashita JK. In Vitro Modeling of Blood-Brain Barrier with Human iPSC-Derived Endothelial Cells, Pericytes, Neurons, and Astrocytes via Notch Signaling. Stem Cell Rep. 2017; 8:634-647.

17. Cecchelli R, Berezowski V, Lundquist S, Culot M, Renftel M, Dehouck M-P, Fenart L. Modelling of the Blood-Brain Barrier in Drug Discovery and Development. Nat. Rev. Drug Discovery. 2007; 6:650-661. [PubMed: 17667956]

18. Weksler BB, Subileau EA, Perrière N, Charneau P, Holloway K, Leveque M, Tricoire-Leignel H, Nicotra A, Bourdoulous S, Turowski P, Male DK, Roux F, Greenwood J, Romero IA, Couraud PO. Blood-Brain Barrier-Specific Properties of a Human Adult Brain Endothelial Cell Line. FASEB J. 2005; 19:1872-1874. [PubMed: 16141364]

19. Aday S, Cecchelli R, Hallier-Vanuxeem D, Dehouck MP, Ferreira L. Stem Cell-Based Human Blood-Brain Barrier Models for Drug Discovery and Delivery. Trends Biotechnol. 2016; 34:382_ 393. [PubMed: 26838094]

20. Lippmann ES, Azarin SM, Kay JE, Nessler RA, Wilson HK, Al-Ahmad A, Palecek SP, Shusta EV. Derivation of Blood-Brain Barrier Endothelial Cells from Human Pluripotent Stem Cells. Nat. Biotechnol. 2012; 30:783-791. [PubMed: 22729031]

21. Wang YI, Abaci HE, Shuler ML. Microfluidic Blood-Brain Barrier Model Provides In Vivo-Like Barrier Properties for Drug Permeability Screening. Biotechnol. Bioeng. 2017; 114:184-194. [PubMed: 27399645]

22. Oberheim NA, Takano T, Han X, He W, Lin JHC, Wang F, Xu Q, Wyatt JD, Pilcher W, Ojemann JG, Ransom BR, Goldman SA, Nedergaard M. Uniquely Hominid Features of Adult Human Astrocytes. J. Neurosci. 2009; 29:3276-3287. [PubMed: 19279265]

23. Han X, Chen M, Wang F, Windrem M, Wang S, Shanz S, Xu Q, Oberheim NA, Bekar L, Betstadt S, Silva AJ, Takano T, Goldman SA, Nedergaard M. Forebrain Engraftment by Human Glial Progenitor Cells Enhances Synaptic Plasticity and Learning in Adult Mice. Cell Stem Cell. 2013; 12:342-353. [PubMed: 23472873]

24. Wuest DM, Wing AM, Lee KH. Membrane Configuration Optimization for a Murine In Vitro Blood-Brain Barrier Model. J. Neurosci. Methods. 2013; 212:211-221. [PubMed: 23131353]

25. Rizzo A, Vasco C, Girgenti V, Fugnanesi V, Calatozzolo C, Canazza A, Salmaggi A, Rivoltini L, Morbin M, Ciusani E. Melanoma Cells Homing to the Brain: an In Vitro Model. BioMed Res. Int. 2015; 2015:476069. [PubMed: 25692137]

26. Strazza M, Maubert ME, Pirrone V, Wigdahl B, Nonnemacher MR. Co-culture Model Consisting of Human Brain Microvascular Endothelial and Peripheral Blood Mononuclear Cells. J. Neurosci. Methods. 2016; 269:39-45. [PubMed: 27216631]

27. Kelley LC, Lohmer LL, Hagedorn EJ, Sherwood DR. Traversing the Basement Membrane In Vivo: A Diversity of Strategies. J. Cell Biol. 2014; 204:291-302. [PubMed: 24493586]

28. Morris GE, Bridge JC, Brace LA, Knox AJ, Aylott JW, Brightling CE, Ghaemmaghami AM, Rose FRAJ. A Novel Electrospun Biphasic Scaffold Provides Optimal Three-Dimensional Topography for In Vitro Co-Culture of Airway Epithelial and Fibroblast Cells. Biofabrication. 2014; 6:035014. [PubMed: 24925127]

29. Obermeier B, Daneman R, Ransohoff RM. Development, Maintenance and Disruption of the Blood-Brain Barrier. Nat. Med. 2013; 19:1584-1596. [PubMed: 24309662]

30. Gaston JD, Bischel LL, Fitzgerald LA, Cusick KD, Ringeisen BR, Pirlo RK. Gene Expression Changes in Long-Term in Vitro Human Blood-Brain Barrier Models and Their Dependence on a Transwell Scaffold Material. J. Healthc. Eng. 2017; 2017:5740975. [PubMed: 29317995]

31. Pensabene V, , Crowder SW, , Balikov DA, , Lee JB, , Sung HJ. Proceedings of the Annual International Conference of the IEEE Engineering in Medicine and Biology Society EMBS; 2016 Optimization of Electrospun Fibrous Membranes for In Vitro Modeling of Blood-Brain Barrier; 125128 
32. Bischel LL, Coneski PN, Lundin JG, Wu PK, Giller CB, Wynne J, Ringeisen BR, Pirlo RK. Electrospun Gelatin Biopapers as Substrate for In Vitro Bilayer Models of Blood-Brain Barrier Tissue. J. Biomed. Mater. Res., Part A. 2016; 104:901-909.

33. Wu S, Wang Y, Streubel PN, Duan B. Living Nanofiber Yarn-Based Woven Biotextiles for Tendon Tissue Engineering Using Cell Tri-culture and Mechanical Stimulation. Acta Biomater. 2017; 62:102-115. [PubMed: 28864251]

34. Chen C, Jiang P, Xue H, Peterson SE, Tran HT, McCann AE, Parast MM, Li S, Pleasure DE, Laurent LC, Loring JF, Liu Y, Deng W. Role of Astroglia in Down's Syndrome Revealed by Patient-Derived Human-Induced Pluripotent Stem Cells. Nat. Commun. 2014; 5:4430. [PubMed: 25034944]

35. Wu S, Xu R, Duan B, Jiang P. Three-Dimensional Hyaluronic Acid Hydrogel-Based Models for In Vitro Human iPSC-Derived NPC Culture and Differentiation. J. Mater. Chem. B. 2017; 5:38703878. [PubMed: 28775848]

36. Jiang P, Chen C, Liu X-B, Pleasure DE, Liu Y, Deng W. Human iPSC-Derived Immature Astroglia Promote Oligodendrogenesis by Increasing TIMP-1 Secretion. Cell Rep. 2016; 15:1303-1315. [PubMed: 27134175]

37. Gould ST, Matherly EE, Smith JN, Heistad DD, Anseth KS. The Role of Valvular Endothelial Cell Paracrine Signaling and Matrix Elasticity on Valvular Interstitial. Biomaterials. 2014; 35:35963606. [PubMed: 24462357]

38. Sun H, Mei L, Song C, Cui X, Wang P. The In Vivo Degradation, Absorption and Excretion of PCL-Based Implant. Biomaterials. 2006; 27:1735-1740. [PubMed: 16198413]

39. Yang J, Ju B, Yan Y, Xu H, Wu S, Zhu D, Cao D, Hu J. Neuroprotective Effects of Phenylethanoid Glycosides in an In Vitro Model of Alzheimer's Disease. Exp. Ther. Med. 2017; 13:2423-2428. [PubMed: 28565858]

40. Wu S, Peng H, Li X, Streubel PN, Liu Y, Duan B. Effect of Scaffold Morphology and Cell CoCulture on Tenogenic Differentiation of HADMSC on Centrifugal Melt Electrospun Poly (L-lactic acid) Fibrous Meshes. Biofabrication. 2017; 9:044106. [PubMed: 29134948]

41. Stoll S, Delon J, Brotz TM, Germain RN. Dynamic Imaging of T cell-Dendritic Cell Interactions in Lymph Nodes. Science. 2002; 296:1873-1876. [PubMed: 12052961]

42. Luissint A-C, Artus C, Glacial F, Ganeshamoorthy K, Couraud P-O. Tight Junctions at the Blood Brain Barrier: Physiological Architecture and Disease-Associated Dysregulation. Fluids Barriers CNS. 2012; 9:23. [PubMed: 23140302]

43. Patabendige A, Skinner RA, Morgan L, Abbott NJ. A Detailed Method for Preparation of a Functional and Flexible Blood-Brain Barrier Model Using Porcine Brain Endothelial Cells. Brain Res. 2013; 1521:16-30. [PubMed: 23603406]

44. Lao CD, Friedman J, Tsien CI, Normolle DP, Chapman C, Cao Y, Lee O, Schipper M, Van Poznak C, Hamstra D, Lawrence T, Hayman J, Redman BG. Concurrent Whole Brain Radiotherapy and Bortezomib for Brain Metastasis. Radiat. Oncol. 2013; 8:204. [PubMed: 23965287]

45. Glantz MJ, Chamberlain MC, Chang SM, Prados MD, Cole BF. The Role of Paclitaxel in the Treatment of Primary and Metastatic Brain Tumors. Semin. Radiat. Oncol. 1999; 9:27-33. [PubMed: 10210537]

46. Rice A, Michaelis ML, Georg G, Liu Y, Turunen B, Audus KL. Overcoming the Blood-Brain Barrier to Taxane Delivery for Neurodegenerative Diseases and Brain Tumors. J. Mol. Neurosci. MN. 2003; 20:339-344. [PubMed: 14501017]

47. Foran E, Kwon DY, Nofziger JH, Arnold ES, Hall MD, Fischbeck KH, Burnett BG. CNS Uptake of Bortezomib is Enhanced by P-glycoprotein Inhibition: Implications for Spinal Muscular Atrophy. Neurobiol. Dis. 2016; 88:118-124. [PubMed: 26792401]

48. Belloni D, Veschini L, Foglieni C, Dell'Antonio G, Caligaris-Cappio F, Ferrarini M, Ferrero E. Bortezomib Induces Autophagic Death in Proliferating Human Endothelial Cells. Exp. Cell Res. 2010; 316:1010-1018. [PubMed: 19917281]

49. Rosenberg GA. Neurological Diseases in Relation to the Blood-Brain Barrier. J. Cereb. Blood Flow Metab. 2012; 32:1139-1151. [PubMed: 22252235] 
50. Chen W, Chan Y, Wan W, Li Y, Zhang C. Abeta1-42 Induces Cell Damage via RAGE-Dependent Endoplasmic Reticulum Stress in bEnd.3 cells. Exp. Cell Res. 2018; 362:83-89. [PubMed: 29154819]

51. Yamazaki Y, Kanekiyo T. Blood-Brain Barrier Dysfunction and the Pathogenesis of Alzheimer's Disease. Int. J. Mol. Sci. 2017; 18:9.doi: 10.3390/ijms18091965

52. Serrano-Pozo A, Frosch MP, Masliah E, Hyman BT. Neuropathological Alterations in Alzheimer Disease. Cold Spring Harbor Perspect. Med. 2011; 1:a006189.

53. Deane R, Bell RD, Sagare A, Zlokovic BV. Clearance of Amyloid-Beta Peptide across the BloodBrain Barrier: Implication for Therapies in Alzheimer's Disease. CNS Neurol. Disord.: Drug Targets. 2009; 8:16-30. [PubMed: 19275634]

54. Kumar S, Walter J. Phosphorylation of Amyloid Beta (Abeta) Peptides - A Trigger for Formation of Toxic Aggregates in Alzheimer's Disease. Aging. 2011; 3:803-812. [PubMed: 21869458]

55. Bischel LL, Coneski PN, Lundin JG, Wu PK, Giller CB, Wynne J, Ringeisen BR, Pirlo RK. Electrospun Gelatin Biopapers as Substrate for In Vitro Bilayer Models of Blood-Brain Barrier Tissue. J. Biomed. Mater. Res., Part A. 2016; 104:901-909.

56. Appelt-Menzel A, Cubukova A, Günther K, Edenhofer F, Piontek J, Krause G, Stüber T, Walles H, Neuhaus W, Metzger M. Establishment of a Human Blood-Brain Barrier Co-culture Model Mimicking the Neurovascular Unit Using Induced Pluri- and Multipotent Stem Cells. Stem Cell Rep. 2017; 8:894-906.

57. Minami H, Tashiro K, Okada A, Hirata N, Yamaguchi T, Takayama K, Mizuguchi H, Kawabata K. Generation of Brain Microvascular Endothelial-Like Cells from Human Induced Pluri-potent Stem Cells by Co-Culture with C6 Glioma Cells. PLoS One. 2015; 10:e0128890. [PubMed: 26061227]

58. Paradis A, Leblanc D, Dumais N. Optimization of an In Vitro Human Blood-Brain Barrier Model: Application to Blood Monocyte Transmigration Assays. MethodsX. 2016; 3:25-34. [PubMed: 26865992]

59. Helms HC, Abbott NJ, Burek M, Cecchelli R, Couraud P-O, Deli MA, Förster C, Galla HJ, Romero IA, Shusta EV, Stebbins MJ, Vandenhaute E, Weksler B, Brodin B. In Vitro Models of the Blood-Brain Barrier: An Overview of Commonly Used Brain Endothelial Cell Culture Models and Guidelines for Their Use. J. Cereb. Blood Flow Metab. 2016; 36:862-890. [PubMed: 26868179]

60. Hatherell K, Couraud P-O, Romero IA, Weksler B, Pilkington GJ. Development of a ThreeDimensional, All-Human In Vitro Model of the Blood-Brain Barrier Using Mono-, Co-, and TriCultivation Transwell Models. J. Neurosci. Methods. 2011; 199:223-229. [PubMed: 21609734]

61. Bhowmik A, Khan R, Ghosh MK. Blood Brain Barrier: A Challenge for Effectual Therapy of Brain Tumors. BioMed Res. Int. 2015; 2015:320941. [PubMed: 25866775]

62. Weidle UH, Niewohner J, Tiefenthaler G. The Blood-Brain Barrier Challenge for the Treatment of Brain Cancer, Secondary Brain Metastases, and Neurological Diseases. Cancer Genomics Proteomics. 2015; 12:167-177. [PubMed: 26136217]

63. Fellner S, Bauer B, Miller DS, Schaffrik M, Fankhänel M, Spruß T, Bernhardt G, Graeff C, Färber L, Gschaidmeier H, Buschauer A, Fricker G. Transport of Paclitaxel (Taxol) across the BloodBrain Barrier In Vitro and In Vivo. J. Clin. Invest. 2002; 110:1309-1318. [PubMed: 12417570]

64. Wang W, Cho H-Y, Rosenstein-Sisson R, Ramos NIM, Price R, Hurth K, Schönthal AH, Hofman FM, Chen TC. Intratumoral Delivery of Bortezomib: Impact on Survival in an Intracranial Glioma Tumor Model. J. Neurosurg. 2018; 128:695-700. [PubMed: 28409734]

65. Rehman M, Madni A, Shi D, Ihsan A, Tahir N, Chang KR, Javed I, Webster TJ. Enhanced Blood Brain Barrier Permeability and Glioblastoma Cell Targeting via Thermoresponsive Lipid Nanoparticles. Nanoscale. 2017; 9:15434-15440. [PubMed: 28976512]

66. Chen W, Chan Y, Wan W, Li Y, Zhang C. Abeta1-42 Induces Cell Damage via RAGE-Dependent Endoplasmic Reticulum Stress in bEnd.3 cells. Exp. Cell Res. 2017; 362:83. [PubMed: 29154819]

67. Mawuenyega KG, Sigurdson W, Ovod V, Munsell L, Kasten T, Morris JC, Yarasheski KE, Bateman RJ. Decreased Clearance of CNS Beta-Amyloid in Alzheimer's Disease. Science. 2010; 330:1774. [PubMed: 21148344]

68. Sagare AP, Bell RD, Zlokovic BV. Neurovascular Defects and Faulty Amyloid-Beta Vascular Clearance in Alzheimer's Disease. J. Alzheimer's Dis. 2013; 33:S87-S100. [PubMed: 22751174] 
69. Orlova VV, Drabsch Y, Freund C, Petrus-Reurer S, van den Hil FE, Muenthaisong S, Dijke PT, Mummery CL. Functionality of Endothelial Cells and Pericytes from Human Pluripotent Stem Cells Demonstrated in Cultured Vascular Plexus and Zebrafish Xenografts. Arterioscler., Thromb. Vasc. Biol. 2014; 34:177-186. [PubMed: 24158517] 

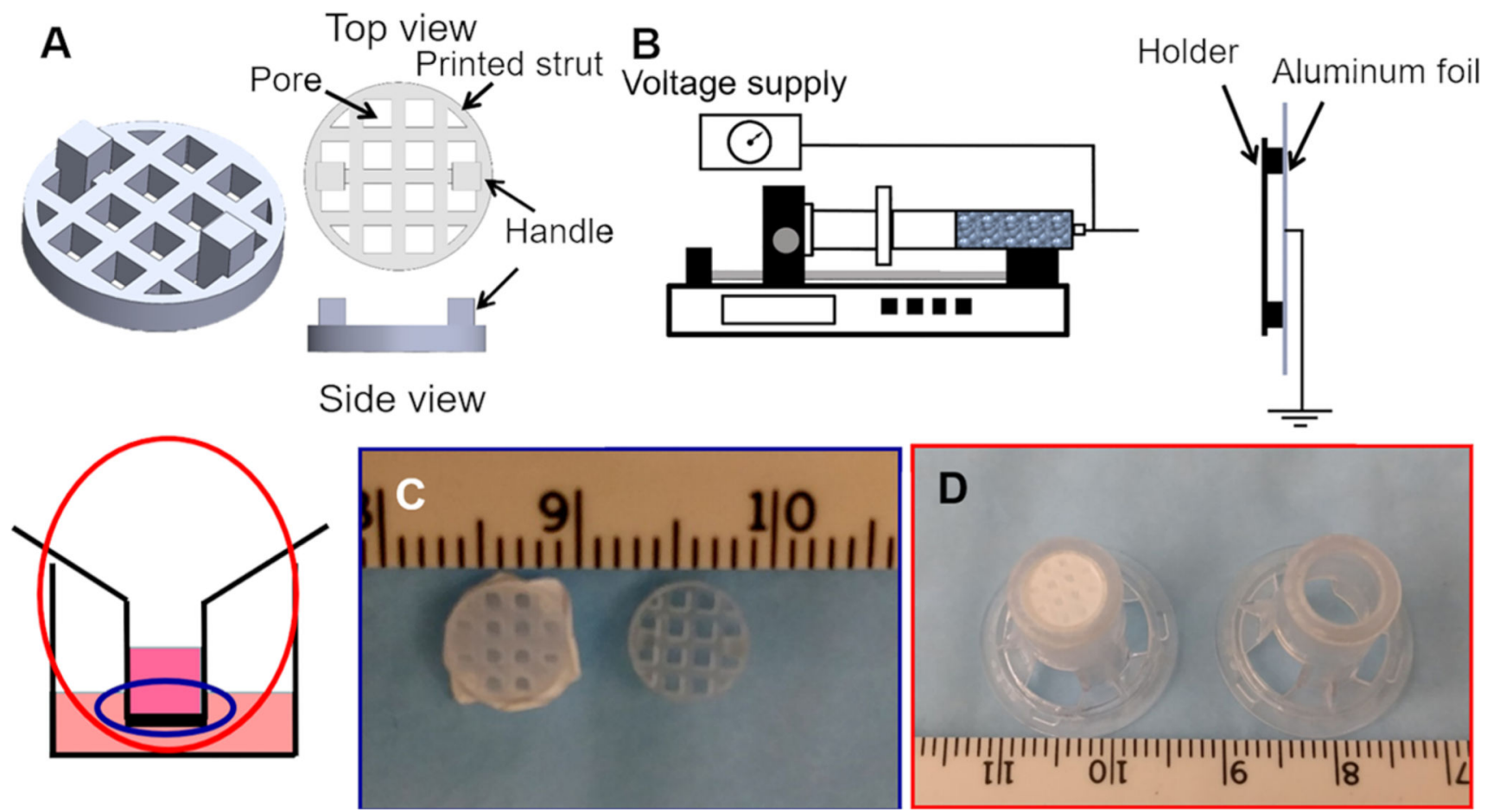

Figure 1.

Fabrication of the insert consisting of a 3D-printed holder and an electrospun PLGA mesh for the BBB model: (A) design of a holder that can fit into a commercial transwell frame. The holder has pore and strut areas with two handles for handling; (B) schematic of electrospinning PLGA nanofibers onto the holder. The holder is fixed onto the aluminum foil on the collector; (C) the insert with the PLGA mesh (left) and an empty holder without the mesh (right); and (D) the inserts were placed into the commercial transwell frame after removing the plastic membranes. Left: insert with the holder and PLGA mesh; Right: insert only. 

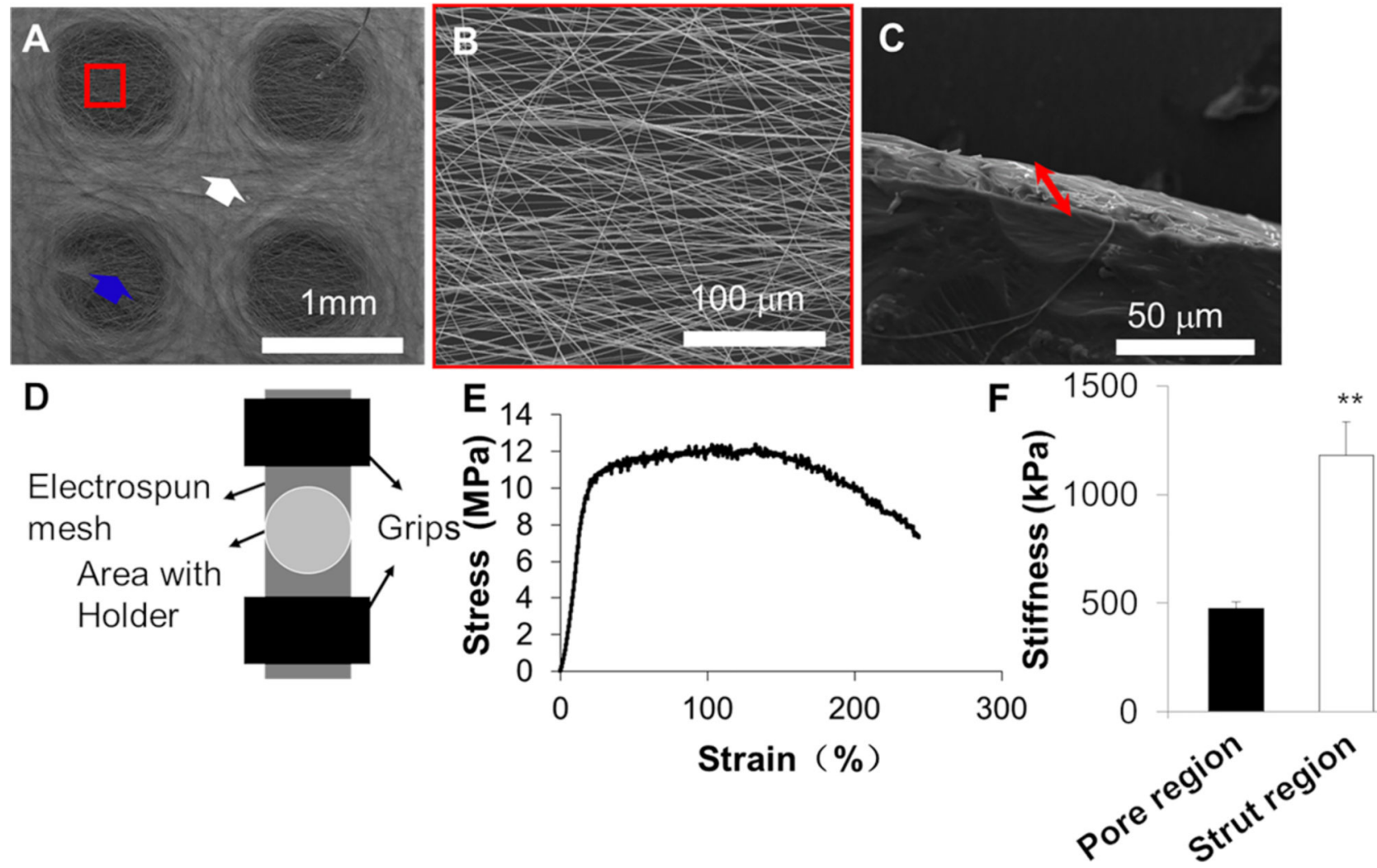

Figure 2.

Characterization of nanofibrous PLGA meshes electrospun onto the holders: (A-C) typical SEM micrographs of the PLGA mesh. (A) Overview of the morphology. Two areas with similar fibrous morphology but different thicknesses were observed. The white arrow indicates the strut region with a thicker thickness, and the red frame and blue arrow indicate the pore region with thinner thickness; (B) close view of the pore region; (C) side view of the pore region, showing the thickness of the PLGA mesh; (D) schematic of the tensile test of PLGA meshes peeled from holders; (E) typical tensile stress-strain curve; and (F) stiffness of the pore region and strut region tested by nanoindentation ( $\sim 50$ points from three different samples, $* * p<0.01)$. 

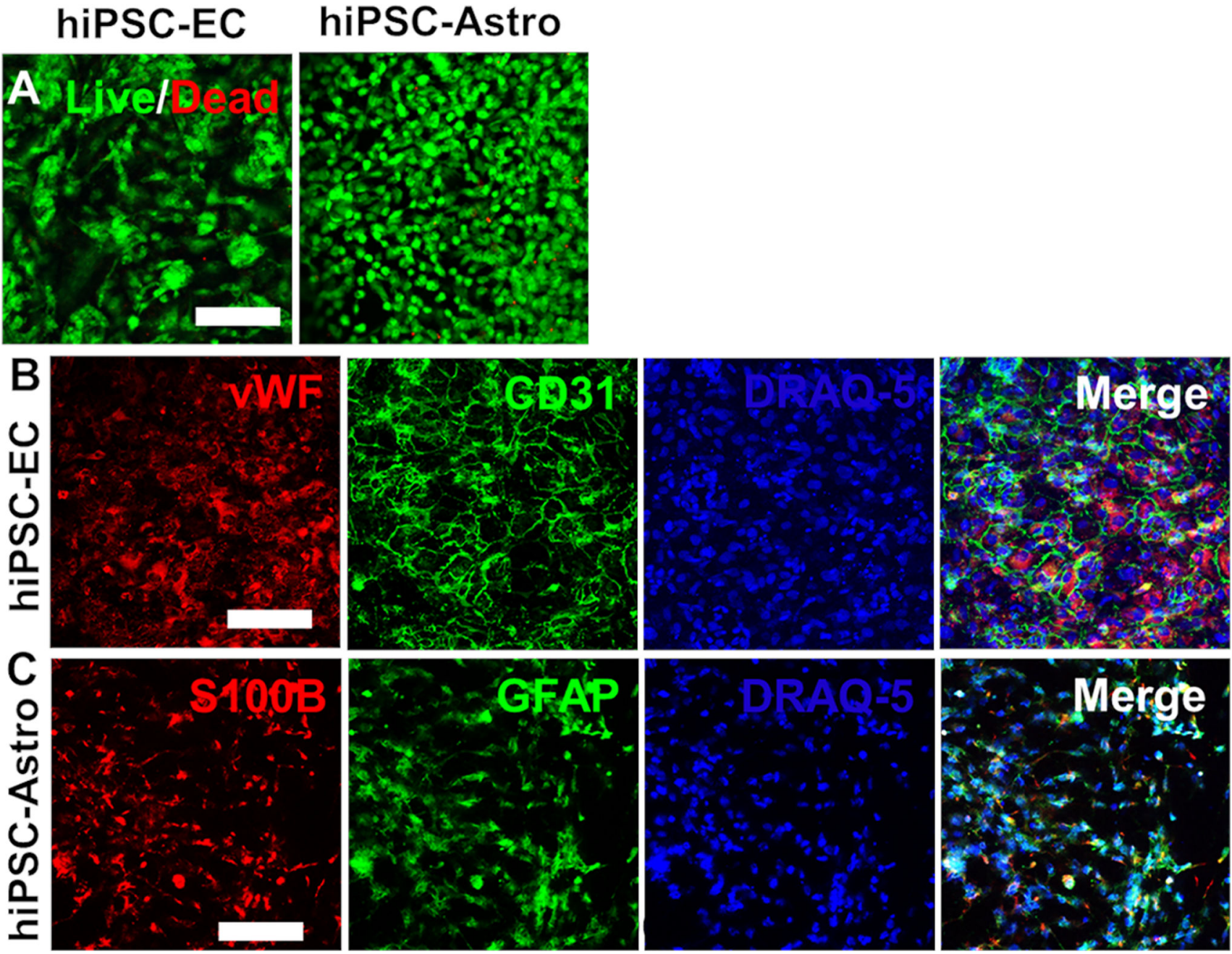

Figure 3.

Cell viability and phenotypic marker expression of hiPSC-ECs and hiPSC-Astro on nanofibrous PLGA meshes: (A) Live/Dead assay images (scale bar: $100 \mu \mathrm{m})$ and (B,C) typical IF images, showing the expression of vWF (red), CD31 (green) for hiPSC-EC and S100B (red), GFAP (green) for hiPSC-Astro (scale bar: $100 \mu \mathrm{m}$ ). 


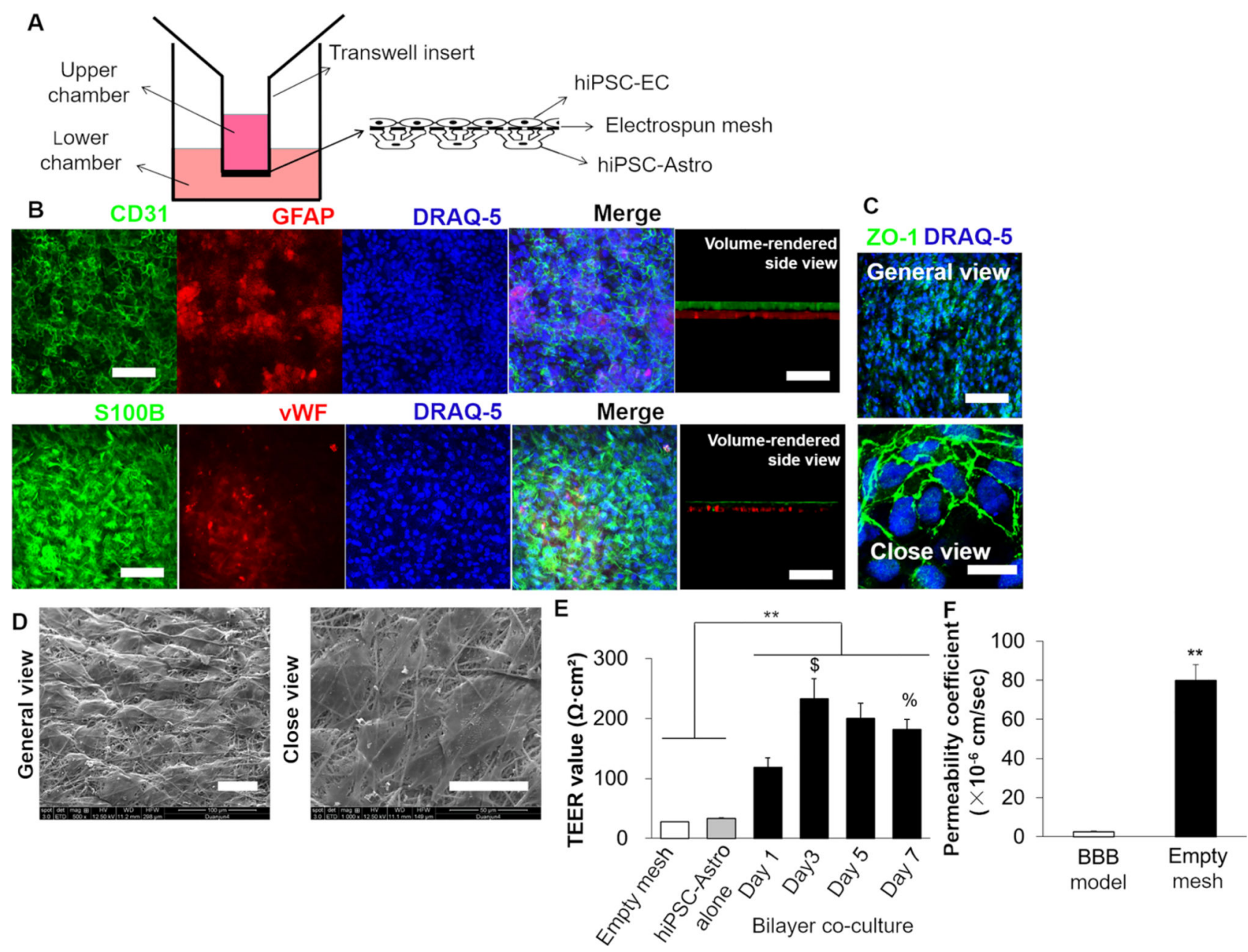

Figure 4.

Generation and characterization of the in vitro BBB model: (A) schematic of a coculture of hiPSC-ECs and hiPSC-Astro on the PLGA mesh that was electrospun onto the 3D-printed holder and fit into the transwell frame. Human iPSC-ECs were cultured on the top side of the PLGA mesh and conditioned in EGM in the upper chamber, whereas hiPSC-Astro were cultured in the bottom side in astrocyte medium in the lower chamber; (B) IF staining of cocultured hiPSC-ECs and hiPSC-Astro after 7 day culture. In the upper panel, the BBB model was costained with CD31 for hiPSC-ECs and GFAP for hiPSC-Astro, whereas in the lower panel, S100B and vWF were stained for hiPSC-Astro and hiPSC-ECs, respectively. Volume-rendered side views of the bilayer cells were also presented (scale bar: $100 \mu \mathrm{m}$ ); (C) expression of the tight junction protein ZO-1 in the cocultured hiPSC-EC (scale bar: $100 \mu \mathrm{m}$ for general view, and $20 \mu \mathrm{m}$ for close view); (D) hiPSC-EC morphology on the electrospun PLGA mesh after 7 day coculture (scale bar: $50 \mu \mathrm{m}$ ); (E) TEER value of the empty mesh, without cells, in the transwell insert (white), BBB model with hiPSC-Astro alone (gray), and with coculture of hiPSC-ECs and hiPSC-Astro at different time points (black) $(n=3-5, * * p$ $<0.01$, \$ indicates a significant difference between days 1 and 3, \% indicates a significant difference between days 3 and 7); and (F) permeability coefficient of sodium fluorescein through the in vitro BBB model $(n=3-5, * * p<0.01)$. 
A<smiles>C1CCCCCC1</smiles>

BBB model

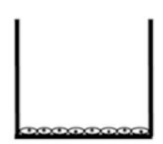

U87MG

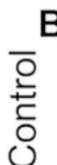

Figure 5.

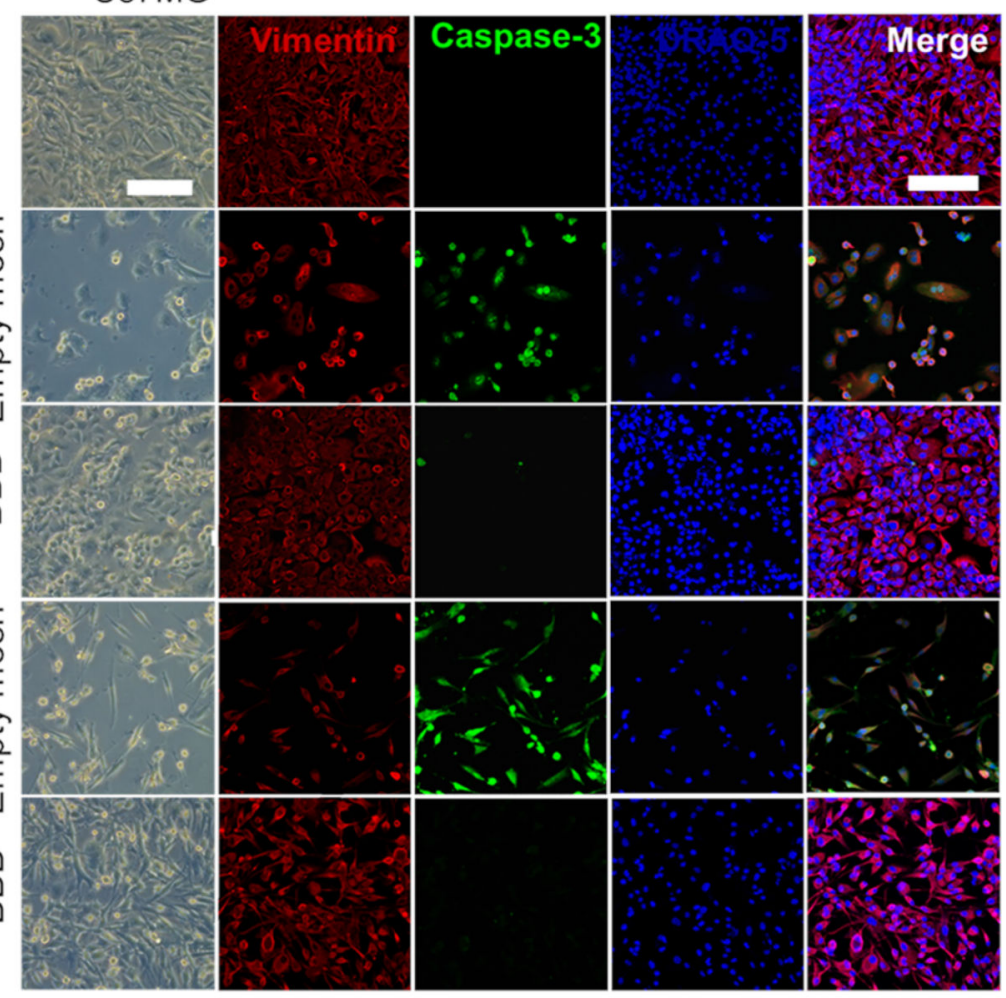

Barrier functions of the in vitro BBB model to PTX and BTZ: (A) schematic of a triculture of hiPSC-ECs and hiPSC-Astro on the PLGA mesh in the upper chamber with U87MG cells in the lower chamber of a transwell insert and the addition of PTX and BTZ. The upper chamber was filled with EGM and the lower chamber was filled with astrocyte medium; (B) typical images of U87MG response to the treatment of PTX $(1 \mu \mathrm{g} / \mathrm{mL})$ and BTZ $(4 \mu \mathrm{g} / \mathrm{mL})$ with or without the BBB model. Left one panel: optical images (scale bar: $100 \mu \mathrm{m}$ ); right four panels: IF staining images (scale bar: $100 \mu \mathrm{m})$; (C) LDH assay showed cytotoxicity $(n=$ $3, * * p<0.01)$; (D) MTT assay showed cell metabolic activity $(n=3, * * p<0.01)$; and (E) TEER value with changing the dose of PTX and BTZ $(n=3, * * p<0.01)$. The dashed line indicates the average TEER value without the addition of anti-GBM drugs.

ACS Appl Mater Interfaces. Author manuscript; available in PMC 2018 July 19. 

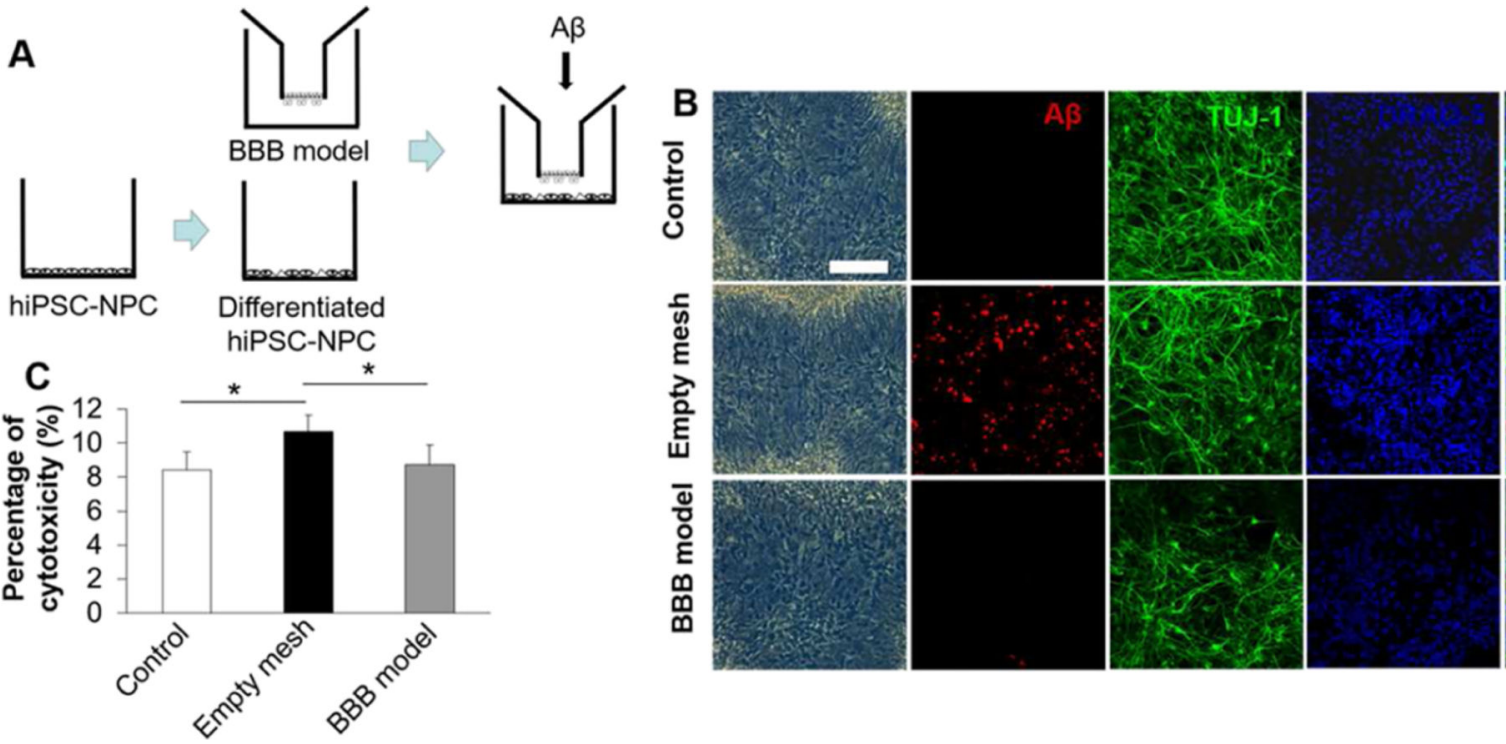

Figure 6.

Barrier functions of the in vitro $\mathrm{BBB}$ model to $\mathrm{A} \beta$ : (A) schematic of a triculture of hiPSCECs and hiPSC-Astro on the PLGA mesh in the upper chamber with hiPSC-NPCs in the lower chamber of a transwell insert and the addition of $\mathrm{A} \beta$; hiPSC-NPCs were induced in neuronal differentiation medium for 14 days before triculture. The upper chamber was filled with EGM and the lower chamber was filled with neuronal differentiation medium; (B) typical images of hiPSC-NPC response to the treatment of $\mathrm{A} \beta$ with or without the $\mathrm{BBB}$ model. Left one panel: optical images (scale bar: $100 \mu \mathrm{m}$ ); right four panels: IF staining images (scale bar: $100 \mu \mathrm{m})$; and (C) LDH assay showed cytotoxicity $(n=3, * p<0.05$ ). Control indicates the group without electrospun meshes, hiPSC-ECs, hiPSC-Astro, and without $\mathrm{A} \beta$ treatment; the empty mesh indicates the group with electrospun meshes but without hiPSC-ECs, hiPSC-Astro, and with $\mathrm{A} \beta$ treatment; and the $\mathrm{BBB}$ model indicates the group with electrospun meshes, hiPSC-ECs, hiPSC-Astro, and with A $\beta$ treatment. 